\title{
Plasma concentrations of endogenous heparinoids in portal hypertension
}

\author{
R F McKee, S Hodson, J Dawes, O J Garden, D C Carter
}

\begin{abstract}
Bleeding as a complication of liver disease can occur in the absence of recognised haemostatic defects. It is now possible to measure the concentration of endogenous heparinoid substances in the blood using a competitive binding assay. One such substance, heparan sulphate (normal range $<600 \mathrm{ng} / \mathrm{ml}$ ) was assayed in the plasma of $\mathbf{4 9}$ patients admitted because of oesophageal varices. In 27 patients with recent upper gastrointestinal bleeding the median plasma heparan sulphate value was $1700 \mathrm{ng} / \mathrm{ml}$ (interquartile (IQ) range 900-3900) compared with $390 \mathrm{ng} / \mathrm{ml}$ (IQ range $256-800$ ) in 22 patients with no recent bleed $(p<0 \cdot 01)$. As heparan sulphate is metabolised by the same route as exogenous heparin, an attempt to establish a cause for the raised heparan concentrations was made by measuring the clearance of exogenous heparin in 10 portal hypertensive patients and 10 controls. The median half life of heparin in plasma in the portal hypertensive patients ( 25.5 minutes; IQ range 22-34) was significantly longer $(p<0.007)$ than the median half life in the controls (18.7 minutes; IQ range 17-21.5). Thus, there is evidence of raised concentrations of endogenous heparin like substances in portal hypertensive patients after gastrointestinal bleeding. These high concentrations may result from reduced hepatic clearance.

(Gut 1992; 33: 1549-1552)
\end{abstract}

It has been recognised for many years that abnormal bleeding and coagulation problems are associated with liver disease. In a recent review, Kelly and Tuddenham ${ }^{1}$ highlighted the large number of coagulation abnormalities that may occur in liver disease and showed that these may be inter-related. Nonetheless, bleeding problems may also occur in the absence of obvious coagulation abnormalities. In a study of 200 patients, Ewe $^{2}$ could find no correlation between 'liver bleeding time' at laparoscopic biopsy and standard coagulation tests.

Heparan sulphate is a highly sulphated endogenous heparinoid which normally constitutes a small proportion of the free fraction of plasma glycosaminoglycans. ${ }^{3}$ It is found in high concentration in endothelial cells and has some anticoagulant activity. Its function is not fully understood, but its presence in blood vessels suggests a role in the prevention of intravascular thrombosis. In several reports abnormal bleeding has been found in the presence of high heparan sulphate values. ${ }^{5-7}$

A new assay has recently been developed to measure the plasma heparin concentration ${ }^{89}$ and has been modified to quantitate plasma heparan sulphate. ${ }^{10} \mathrm{~A}$ wide range of patient samples was screened on a pilot basis for heparan sulphate values and a number of patients with liver disease were noted to have very high concentrations. Two studies have therefore been performed. In the first, plasma heparan sulphate concentrations were measured in a number of patients with portal hypertension and the values obtained compared with a clinical assessment of liver function. The second study compared heparin clearance rates in patients with liver disease and normal controls.

\section{Patients and methods}

\section{HEPARAN SULPHATE VALUES}

In the first study, blood samples were taken from a consecutive series of 49 patients admitted for treatment of oesophageal varices. These patients were admitted either as emergencies because of gastrointestinal bleeding or electively for injection sclerotherapy for oesophogeal varices.

On admission to the University Department of Surgery, Glasgow Royal Infirmary, citrated plasma was prepared from $9 \mathrm{ml}$ of blood and stored at $-20^{\circ} \mathrm{C}$ until analysis. The detailed clinical status of each patient at the time of blood sampling was recorded together with the aetiology of the portal hypertension. In 38 patients, liver biopsy had been performed but in 11 this was not possible because of coagulation defects, and the aetiology of their portal hypertension had been established by a combination of clinical history, liver function tests, autoimmune screening, and radiology. The date of the most recent episode of upper gastrointestinal bleeding was recorded, along with its cause. All patients with portal hypertension admitted to the unit with gastrointestinal bleeding that required blood transfusion underwent endoscopy for diagnosis. The results of full blood count, coagulation screen, urea and electrolytes, liver function tests, and serum albumin were recorded. Each patient was assessed clinically for the presence of ascites or encephalopathy at the time of admission so that they could be assigned to a modified Child's grade as described by Pugh." Any transfusion of blood or blood products within the week before blood sampling was noted.

Blood samples for determination of plasma heparan sulphate concentrations were also taken from a control group of 10 patients with normal liver function who had had a gastrointestinal bleed requiring at least $2 \mathrm{U}$ of blood within the seven days before sampling.

Plasma heparan sulphate concentrations were measured by the method described by Reilly et al. ${ }^{10}$ Samples were pretreated with pronase (Sigma; $5 \mathrm{mg} / \mathrm{ml}$ ) at $37^{\circ} \mathrm{C}$ for 16 hours. They were 
then frozen to $-20^{\circ} \mathrm{C}$ and thawed before assay. Highly sulphated glycosaminoglycans in the sample competed with BS125TBI HeS A (a gift from Dr E A Johnson, National Institutes for Biological Standards and Control, London, UK) for binding to Polybrene-sepharose $e^{9}$ in $0.05 \mathrm{M}$ phosphate buffer, pH $7 \cdot 4$, containing $1 \%$ Tween 20 and $2.5 \mathrm{mg} / \mathrm{ml}$ bovine serum albumin (Sigma). The results were assessed against heparan sulphate HTS/435 ( a gift of Dr R Mastacchi, Alfaricchi, Corlo, Italy) as a standard, and expressed as heparan sulphate equivalent (HS equivalents).

Selected samples were treated with chrondroitinase ABC (Sigma) at a concentration of $0.25 \mathrm{U} / \mathrm{ml}$ at $37^{\circ} \mathrm{C}$ for 16 hours before proteolysis with pronase.

The Mann-Whitney $U$ test was used to assess differences between acute and stable groups and the Kruskal-Wallis test used to assess the differences between modified Child's grades.

\section{HEPARIN CLEARANCE}

For the heparin clearance study, 10 age and sex matched pairs were compared. Ten patients with portal hypertension who had experienced previous bleeds from oesophageal varices were studied. The cause of the portal hypertension was biopsy proven liver disease in all 10 . Patients were excluded from the study if they had experienced an episode of bleeding in the previous month or if their coagulation screen was significantly abnormal (prothrombin time $>2$ seconds prolonged). Patients were also excluded if they had significant renal disease or were taking drugs known to affect the liver enzymes or coagulation. Age and sex matched controls were obtained from patients admitted for minor surgery who had normal liver function (serum bilirubin, transaminases, alkaline phosphatase, and gamma glutamyl transferase normal; no drug therapy; and no history of excess alcohol consumption). The study was approved by the Ethical Committee of the Royal Infirmary and informed consent was obtained. Each patient underwent a full physical examination before and after the study. Pulse rate, arterial blood pressure, and temperature were recorded and all current drug therapy was noted. Blood samples were obtained before the study for plasma heparan sulphate determination, full blood count, urea and electrolytes, liver function tests, and coagulation screen. Routine urine analysis was performed before and after the study.

On the day of the study, an indwelling cannula was inserted in the left arm and flushed with saline. A blood sample was taken five minutes later. After a further 10 minutes, $2500 \mathrm{U}$ of sodium heparin were injected as an intravenous bolus into the right arm. Blood samples were taken from the left arm 5, 10, 20,40,80, and 160 minutes after the injection of the heparin. All blood samples were taken into citrate anticoagulant, centrifuged, and the plasma was stored at $-20^{\circ} \mathrm{C}$ till analysis. Heparin values were measured as described by Dawes et $a l^{9}$ using porcine mucosal heparin (Sigma) both for the standard and in preparation of the radiolabel.

For each patient the log of the heparin concen-
TABLE I Characteristics of 49 patients included in the study of plasma heparan sulphate values in patients with portal hypertension

\begin{tabular}{lll}
\hline & $\begin{array}{l}\text { Patients without } \\
\text { recent bleed } \\
(n=22)\end{array}$ & $\begin{array}{l}\text { Patients with } \\
\text { recent bleed } \\
(n=27)\end{array}$ \\
\hline $\begin{array}{l}\text { Age (years) } \\
\quad \text { Mean (+SEM)) }\end{array}$ & $53 \cdot 6(2 \cdot 7)$ & $58 \cdot 5(3 \cdot 0)$ \\
$\begin{array}{l}\text { Sex ratio } \\
\text { (M:F) }\end{array}$ & $16: 6$ & $20: 7$ \\
$\begin{array}{l}\text { Modified Child's grade } \\
\text { (A:B:C) }\end{array}$ & $7: 11: 4$ & $4: 7: 16$ \\
$\begin{array}{l}\text { Aetiology: } \\
\text { Alcoholic cirrhosis }\end{array}$ & 13 & \\
Primary biliary cirrhosis & 2 & 16 \\
$\quad$ Cryptogenic cirrhosis & 4 & 3 \\
$\quad$ Chronic active hepatitis & 2 & 3 \\
$\quad$ Portal vein thrombosis & 1 & 2 \\
$\quad$ Secondary biliary cirrhosis & 0 & 1 \\
Drug induced cirrhosis & 0 & 1 \\
\hline
\end{tabular}

tration was plotted against time and the plasma halflife $\left(t_{1 / 2}\right)$ estimated from the plot. The $t_{1 / 2}$ values for the two groups were compared using the Mann-Whitney U test.

\section{Results}

\section{HEPARAN SULPHATE VALUES}

Digestion of selected samples with chondroitinase $\mathrm{ABC}$ did not destroy their activity in the assay, indicating that heparan sulphate rather than dermatan or chondroitin sulphate was being measured.

Table I shows the characteristics of the patients with liver disease included in the first study. The median plasma heparan sulphate value was $1000 \mathrm{ng} / \mathrm{ml}$ (interquartile (IQ) range $375-3000 \mathrm{ng} / \mathrm{ml}$ ). In a control population of 30 healthy individuals normal values were less than $600 \mathrm{ng} / \mathrm{ml}$ (median 280; range $<200$ $600 \mathrm{ng} / \mathrm{ml}$ ). Twenty nine of the 49 patients in our study had a plasma heparan sulphate concentration of greater than $600 \mathrm{ng} / \mathrm{ml}$. In 27 patients who had experienced an upper gastrointestinal bleed within the previous 28 days (median 5 days before sampling; IQ range 2-15 days) the median plasma heparan sulphate value was $1700 \mathrm{ng} / \mathrm{ml}$ (IQ range 900-3900) compared with $390 \mathrm{ng} / \mathrm{ml}$ (IQ range 256-800) in 22 patients who had had no recent bleed $(p<0.01)$ (Fig 1). High heparan sulphate concentrations were also associated with poor liver function, as assessed by modified Child's grading (median (IQ range); Child's grade A - $500 \mathrm{ng} / \mathrm{ml}$ (256-1800); grade B - 615 $\mathrm{ng} / \mathrm{ml}(252-1700)$; grade C $-2500 \mathrm{ng} / \mathrm{ml}(620$ 4200)) but this did not reach statistical significance $(\mathrm{p}<0 \cdot 5)$.

There was no association between the plasma heparan sulphate concentration and coagulation

TABLE II Characteristics of the patients with chronic liver disease who had heparin clearance studies performed

\begin{tabular}{ll}
\hline Age (years) & $58 \cdot 8(+3 \cdot 8)$ \\
$\quad($ mean $(+\mathrm{SEM}))$ & \\
Sex ratio $(M: \mathrm{F})$ & $4: 6$ \\
Modified Child's Grade & $9: 1: 0$ \\
(A:B:C) & \\
Aetiology: & 7 \\
Alcoholic cirrhosis & 1 \\
Primary biliary cirrhosis & 2 \\
Cryptogenic cirrhosis & \\
\hline
\end{tabular}




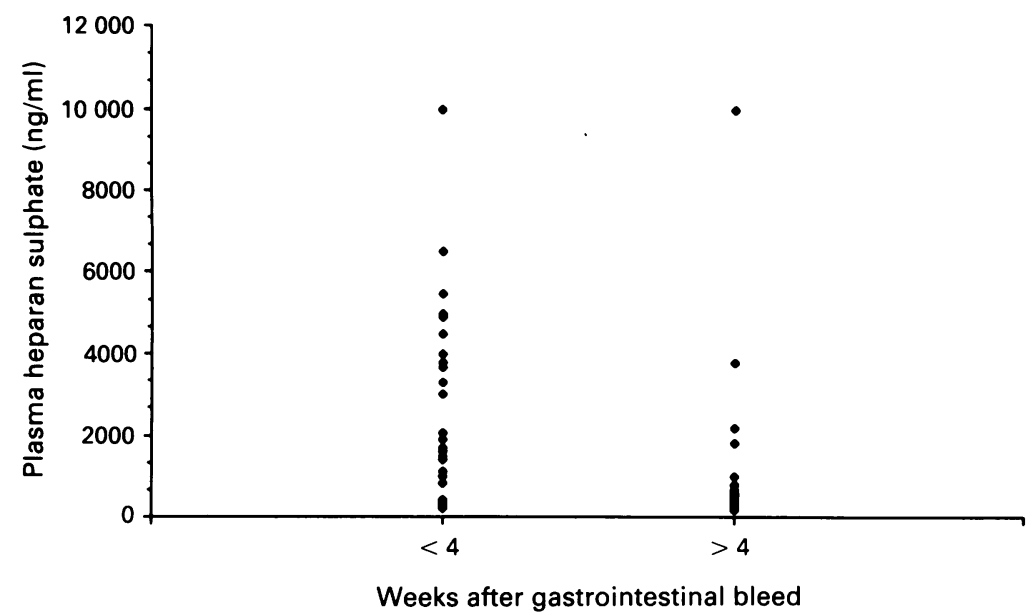

Figure 1: Plasma heparan values in 49 patients with liver disease, 27 of whom had a gastrointestinal bleed within four weeks of blood sampling $(<4)$ and 22 of whom were stable having had no gastrointestinal bleeding for at least four weeks $(>4)$.

screen abnormalities, liver function tests, or the amount of blood transfused. The aetiology of the portal hypertension did not seem to affect the plasma heparan sulphate value, although both the patients whose portal hypertension was caused by portal vein thrombosis had lower plasma heparan sulphate values, one having bled two days previously and the other having been stable for six months. In the 10 patients with normal liver function but recent gastrointestinal bleeding, the median plasma heparan sulphate value was $230 \mathrm{ng} / \mathrm{ml}$ (IQ range $150-330 \mathrm{ng} / \mathrm{ml}$ ).

\section{HEPARIN CLEARANCE}

The characteristics of the 10 liver disease patients on whom heparin clearance studies were performed are shown in Table II. The mean age of the 10 normal controls was 56.5 years (SEN 3.9). Figure 2 compares the $t_{1 / 2}$ for heparin in the age and sex matched pairs of patients. The median half life of heparin in plasma in the portal

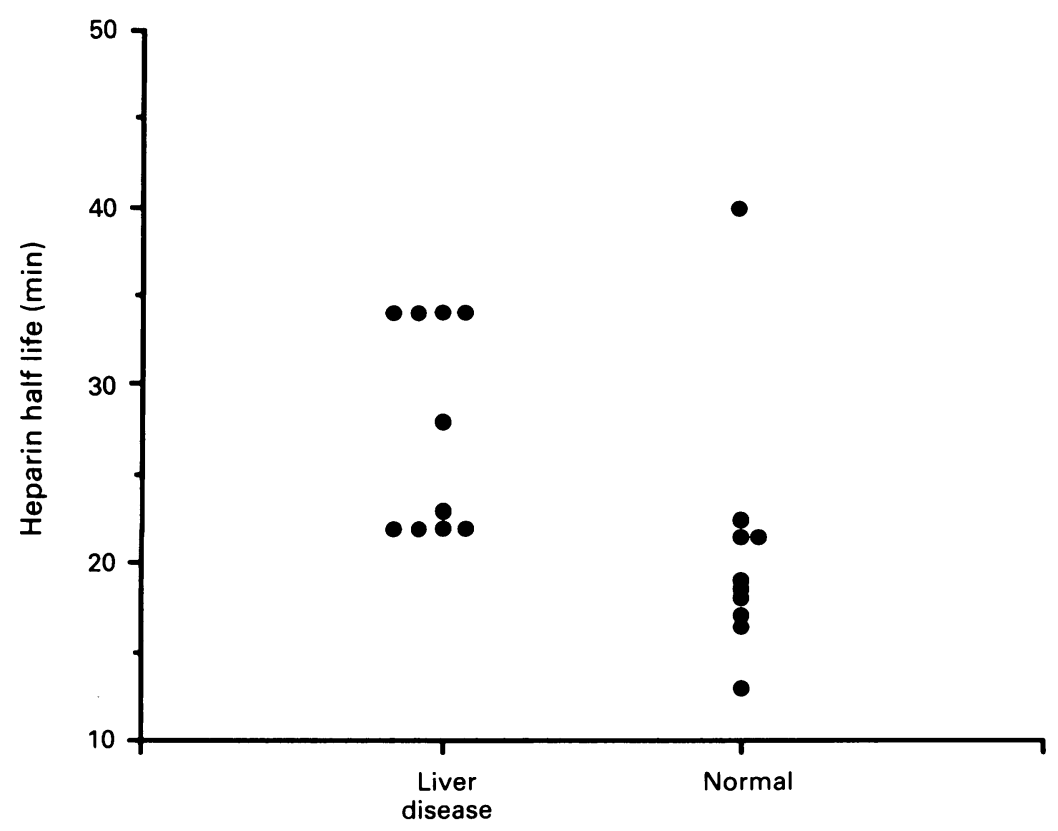

Figure 2: Half-life $\left(t_{1 / 2}\right)$ of $2500 \mathrm{U}$ of intravenous sodium heparin in 10 age and sex matched pairs of patients with and without liver disease. hypertensive patients $(25.5$ minutes (IQ range $22-34)$ ) was significantly longer $(p<0.007)$ than the median half life in the controls $(18.7$ minutes (IQ range 17-21·5)).

\section{Discussion}

In patients with liver disease, both variceal and non-variceal bleeding from the gastrointestinal tract are common clinical problems. ${ }^{12}$ Although abnormal coagulation is a poor prognostic factor for survival in liver disease, 111 the risk of gastrointestinal bleeding in individuals is not well defined. Boks ${ }^{14}$ has shown an association between abnormal coagulation factors and mucosal bleeding but the cause of an episode of variceal bleeding is probably multifactorial. It may be that one of the factors affecting the risk of gastrointestinal bleeding in patients with liver disease is the presence of other local anticoagulant factors. In this study, plasma heparan sulphate values were raised significantly after recent gastrointestinal haemorrhage. Since plasma heparan sulphate concentrations in a control population with recent gastrointestinal bleeding were normal, it seems unlikely that the high values in the patients with liver disease were caused by the bleed alone. This is supported by the observation that plasma values are greater in patients with severe liver disease. It may be that the recent gastrointestinal bleeding has caused further disturbance of liver function and that the high heparan sulphate values are a consequence rather than a cause of the bleed but it is tempting to speculate that this substance may be a local factor in determining bleeding risk in patients with apparently normal coagulation.

The second study was undertaken in an attempt to explain why patients with liver disease might have increased heparan sulphate concentrations. High levels of plasma heparan sulphate in portal hypertension might be the result of increased synthesis or decreased catabolism. The best way of distinguishing between these two possible mechanisms would be to give heparan sulphate and follow the clearance. Heparan sulphate is not yet a licensed therapeutic product, however, and since heparin clearance is probably mediated by the same routes" it was decided to examine heparin clearance in the first instance.

Previous work on heparin clearance in liver disease is contradictory but this may well be because of the use of activity rather than concentration as a measurement of the heparin level. In studies using heparin activity measurements, Simon ${ }^{15}$ found increased clearance of heparin in liver disease whereas Sette ${ }^{16}$ could only demonstrate increased clearance in fulminant hepatic failure but not in chronic liver disease patients. In support of our own findings, Teien ${ }^{17}$ has reported a decrease in heparin clearance when heparin concentration measurements are used.

It therefore seems likely that the increase in plasma heparan sulphate concentrations in some liver disease patients are caused by reduced clearance by the diseased liver. The statistically significant observation of increased plasma half life in these relatively stable cirrhotic patients is underlined by the fact that none had experienced recent upper gastrointestinal bleeds and that they 
had better liver function than most of the patients investigated in the first part of the study.

1 Kelly DA, Tuddenham EGD. Haemostatic problems in liver disease. Gut 1986; 27 : 339-49.

2 Ewe K. Bleeding time after liver biopsy does not correlate with indices of peripheral coagulation. Dig Dis Sci 1981; 26: 388-93.

3 Calatroni A, Donnelly PV, di Ferrante N. The glycosaminoglycans of human plasma. 7 Clin Invest 1969; 48: 332-43.

4 Marcum JA, Rosenberg RD. Anticoagulantly active heparinlike molecules from vascular tissue. Biochemistry 1984; 23 1730-7.

5 Khoory MS, et al. Circulating heparan sulphate proteoglycan anticoagulant from a patient with a plasma cell disorder. anticoagulant from a patient
7 Clin Invest $1980 ; 65: 665-74$

6 Palmer RN, Rick PD, Zeller JA, Grainick HR. Circulating heparan sulphate anticoagulant in a patient with a fata bleeding disorder. N Engl F Med 1984; 310: 1696-9.

7 Bussel JB, et al. A heparin-like anticoagulant in an eight month old boy with acute myeloblastic leukaemia. Am F Hematol 1984; 16: 83-90.

8 Dawes J, Pepper DS. A sensitive, competitive binding assay for exogenous and endogenous heparin. Thromb Res 1982 27: $387-96$.
9 Dawes J, Prowse CV, Pepper DS. The measurement of heparin and other therapeutic sulphated polysaccharides in ost 1985; 54: $630-4$

10 Reilly KM, Dawes J, Yap PL, Barnetson RStC, McGregor IR Release of highly sulphated glycosamingoglycans and histamine from human basophils. Int Arch Allergy App Immunol 1988; 86: 261-6.

11 Pugh RNH, Murray-Lyon IM, Dawson JL, Pietroni MC Williams R. Transection of the oesophagus for oesophageal varices. BrF Surg 1973; 60: 646-9.

12 Novis DH, Duys P, Barbezat GO, Clain J, Bank S, Terblanche J. Fibreoptic endoscopy and the use of the Sengstaken tube in acute gastrointestinal haemorrhage in patients with porta hypertension and oesophageal varices. Gut 1976; 17: 258-63.

13 Garden OJ, Gilmour WH, Carter DC. Factors influencing one year survival following acute variceal haemorrhage. $\mathcal{F} R$ Coll Surg Edinb 1985; 30: 277-82.

14 Boks AL, Brommer EJP, Schalm SW, van Vlist HHDM. Haemostasis and fibrinolysis in severe liver failure and their relation to haemorrhage. Hepatology 1985; 6: 79-86.

15 Simon TL, Hyers TM, Gaston JP, Harker LA. Heparin pharmacokinetics; increased requirements in pulmonary embolism. Brf Haematol 1978; 39: 111-20.

16 Sette H, Hughes RD, Lagley PG, Gimson AES, Williams R. Heparin response and clearance in acute and chronic liver disease. Thromb Haemost 1985; 54: 591-4.

17 Teien AN. Heparin elimination in patients with liver cirrhosis. Thromb Haemost 1977; 38: 701-6. 